\title{
Documentación
}

CIUDAD Y TERRITORIO

ESTUDIOS TERRITORIALES

ISSN(P): 2697-231X; ISSN(E): 2697-2328

Vol. LIII, N.․ㄹㄹ 207 , Monográfico 2021

Págs. 277-296

https://doi.org/10.37230/CyTET.2021.M21.14.2

CC BY-NC-ND

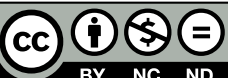

\section{Políticas e instrumentos de fomento de la rehabilitación energética en Francia y Alemania}

\author{
Carolina GarCíA-MADRUGA \\ Patricia Molina-COSTA
}

TECNALIA, Basque Research and Technology Alliance (BRTA)

RESUMEN: El objetivo del artículo es analizar las políticas de apoyo a la rehabilitación energética de viviendas en Francia y Alemania, dos de los países europeos con mayores tasas de renovación. Para ello se analizan los documentos oficiales de la administración central de ambos países, acudiendo a los boletines oficiales y a fuentes primarias de los distintos ministerios o de otros agentes involucrados en el desarrollo y ejecución de las diferentes estrategias sectoriales (energía, vivienda, cambio climático, bienestar social, etc.) que afectan a la política de rehabilitación. Para ambos casos de estudio se incluyen los siguientes ámbitos de análisis: visión global de las políticas de rehabilitación en cada país, instrumentos de financiación, mecanismos para la movilización de agentes y para la activación de la demanda, e identificación de elementos replicables en el contexto español.

PALABRAS CLAVE: Francia; Alemania; Eficiencia energética; Rehabilitación edificatoria; Regeneración urbana; Estrategia a largo plazo.

\section{Policies and tools to promote buildings' energy renovation in France and Germany}

ABSTRACT: The aim of the article is to analyze the policies to support the energy renovation of homes in France and Germany, two of the European countries with the highest renovation rates. For this, the official documents of the central administration of both countries are analyzed, using the official gazettes and primary sources of the different ministries or other agents involved in the development and execution of the different sectoral strategies (energy, housing, climate change, social welfare, etc.) that affect renovation policy. For both case studies, the following areas of analysis are included: global vision of renovation policies in each country, financing instruments, mechanisms for stakeholder engagement and demand activation, and identification of replicable elements in the Spanish context.

KEYWORDS: France; Germany; Energy efficiency; Building renovation; Urban regeneration; Long-term strategy.

Correo electrónico: carolina.garcia@tecnalia.com; N.o ORCID: https://orcid.org/0000-0001-8349-7398 Correo electrónico: patricia.molina@tecnalia.com; N. ORCID: https://orcid.org/0000-0002-6747-2753 


\section{Introducción}

ste artículo se basa en los resultados del "Estudio comparado sobre financiación y políticas de apoyo a la rehabilitación en países de la UE", que forma parte de una serie de trabajos realizados en apoyo a la elaboración de la "Estrategia a largo plazo para la Rehabilitación Energética en el Sector de la Edificación en España" (ERESEE 2020) por parte del Ministerio de Transportes, Movilidad y Agenda Urbana. El objetivo del estudio fue analizar las políticas de apoyo a la rehabilitación energética en Francia y Alemania, por ser dos de los países europeos con mayores tasas de renovación energética de viviendas ${ }^{1}$ y por contar además con una política de renovación y transición energética consolidada (PELEGRY \& MARTínEZ, 2016).

Para realizar el análisis de ambas políticas de rehabilitación, la francesa y la alemana, se han analizado los documentos oficiales de la administración central de ambos países, acudiendo a los boletines oficiales y a fuentes primarias de los distintos ministerios o de otros agentes involucrados en el desarrollo y ejecución de las diferentes estrategias sectoriales (energía, vivienda, cambio climático, bienestar social, etc.) que afectan a la política de rehabilitación. Con el fin de establecer un estudio comparado, para ambos casos de estudio se han incluido los siguientes ámbitos de análisis: visión global de cada país, instrumentos para la financiación de la rehabilitación, mecanismos o instrumentos para la movilización de agentes para la activación de la demanda e identificación de elementos replicables en el caso español.

\section{Políticas e instrumentos de fomento de la rehabilitación en Francia}

\subsection{Visión global de las políticas de rehabilitación}

En Francia, cabe destacar que la rehabilitación se ha abordado desde una triple perspectiva: como parte de las políticas de regeneración urbana de áreas desfavorecidas, como parte de

\footnotetext{
1 Según las fichas técnicas sobre edificios de la UE, la proporción anual del parque de edificios que se somete a una renovación profunda o integral es superior al 1,5\% en países como Alemania, Francia o Austria. (ver: https://ec.europa.eu/ energy/eu-buildings-factsheets en)

${ }^{2}$ La Politique de la Ville se ha venido desarrollando desde finales de los años 1970, hace referencia a la política puesta
}

la política medioambiental (fundamentalmente centrada en cuestiones energéticas), y de la mejora de la vivienda, todas ellas con un claro componente social, de atención a las persones más vulnerables (FIG. 1). Es por ello que las competencias en materia de rehabilitación están distribuidas entre diversos organismos, y la rehabilitación forma parte de planes y programas de diverso alcance. En la FIG. 1, se esquematiza el sistema organizativo de los principales planes y programas que sustentan la política de rehabilitación energética en el contexto francés, así como las Agencias que los gestionan.

\subsection{Política de la ciudad}

Las diferentes estrategias y planes llevados a cabo a lo largo de las últimas décadas desde la Política de la Ciudad (Politique de la Ville ${ }^{2}$, PV) han atendido a modelos y enfoques distintos dependiendo de cada época y de los diferentes contextos políticos, alcanzando, por tanto, resultados muy diversos en función del modelo urbano implícito en cada etapa. Aún así, el objetivo primordial de esta política ha sido reducir la segregación social de las ciudades.

Como parte de la PV se han desarrollado diferentes herramientas e instrumentos de gestión dirigidos a facilitar la implementación de acciones de renovación urbana concretas (MATESANZ, 2015). Si nos remontamos a los primeros años 1990, cabría destacar la implementación de los "Contratos de Ciudad" (Contrats de Ville, CdV). Estos fueron convenios de colaboración entre el Estado y las instituciones locales, a través de los cuales se estableció la base de actuación de la PV a partir de esa década. Con este instrumento de concertación, se pasó en estos años del tratamiento centrado en los barrios a una gestión a escala urbana, y se extendió un enfoque más integral y transversal como modelo de política urbana, frente a la lógica sectorial anterior (CASTRILLO, 2010). Décadas después, en 2007, estos CdV fueron sustituidos por los "Contratos de Cohesion Social" (CUCS) ${ }^{3}$, pasando de ser gestionados por la Agencia Nacional de Renovación Urbana (ANRU) a serlo por la Agencia Nacional para la Cohesion Social y de Igualdad de Oportunidades (ACSE), dejando el enfoque exclusivamente urbanístico para

en marcha por el gobierno para mejorar las zonas urbanas en dificultades y reducir las desigualdades sociales entre los territorios.

3 Definidos en la Ley de relativa a la programación por la Cohesión social de 2007. Observatorio ZRUs, link: https:// sig.ville.gouv.fr/\# 


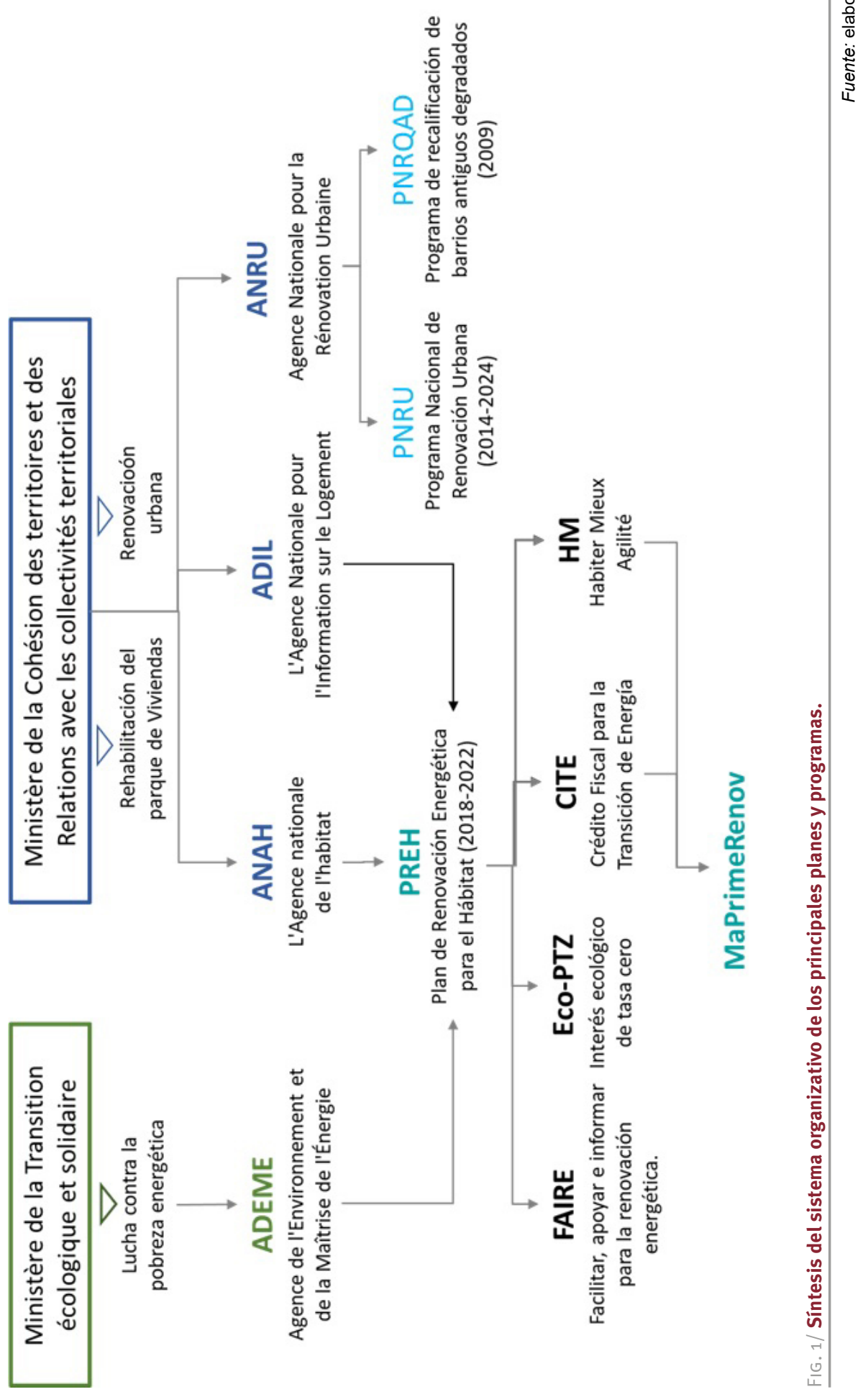


pasar a uno de dinamización y reactivación socioeconómica.

Desde el punto de vista del marco regulatorio, tras la aprobación de la "Ley de Solidaridad y Renovación Urbanas" (Loi relative à la solidarité et au renouvellement urbains, LSRU) en 2000, y siguiendo la misma línea política (mezcla social y reducción de la segregación), se publicó en 2003 la "Ley de orientación y programación de la renovación urbana" (Loi d'orientation et programation de la renovation urbaine, Ley Borloo). Esta última vino acompañada de la creación de la Agencia Nacional de Renovación Urbana (ANRU), encargada de definir y gestionar el Programa Nacional de Renovación Urbana (PNRU), para lo cual contó con un gran presupuesto orientado a reducir las desigualdades sociales. Con este objetivo se procedió a la delimitación y caracterización de Zonas Urbanas Sensibles (Zones Urbaines Sensibles, ZUSs ${ }^{4}$ ). Dicho programa preveía la demolición y reconstrucción de 250.000 viviendas y extendía exenciones fiscales a 85 barrios más. El PNRU se gestionaba a través de los Proyectos de Renovación Urbana (PRU) municipales (iniciados y coordinados por Alcaldía) con el apoyo del delegado territorial de la ANRU y en colaboración con la Agencia para la Vivienda Social (Habitation à loyer moderé, HLM). En 2009 se publicó la Ley de Movilización para la Vivienda y Lucha contra la Exclusión (Loi de mobilisation pour le logement et la lutte contre l'exclusion), en la que se incluyó el Programa Nacional de Recalificación de los Barrios Antiguos Degradados (Programme National de Requalification des Quartiers Anciens Dégradés, PNRQAD), cuyo objeto es recuperar centros antiguos degradados, erradicando las infraviviendas y tratando de aportar mayor diversidad de funciones urbanas y mezcla social.

La financiación estatal para la renovación urbana se proporciona a las autoridades locales sobre la base de un PRU previamente definido y se formaliza mediante la firma de un convenio plurianual con la ANRU. Además, la Agencia y sus distintos socios realizan una evaluación de la integralidad y globalidad del proyecto (en el marco del PNRU o PNRQAD).Por otro lado. la Agencia Nacional de la Vivienda (Agence Nationale de l'Habitat, ANAH) y la Agencia del Medio Ambiente y Gestión de la Energía (Agence de l'Environnement et de la Maîtrise de l'Energie, ADEME) centralizan las ayudas a la rehabilitación de viviendas.

\footnotetext{
4 Se definen como zonas urbanas caracterizadas por la presencia de grandes complejos o áreas de viviendas
}

\subsubsection{Políticas de rehabilitación energética}

En Francia, la Ley del 13 de julio de 2005 sobre el Programa que establece las Orientaciones de la Política Energética (Loi du Programme fixant les Orientations de la Politique Energétique, POPE) fijó como objetivo reducir una cuarta parte las emisiones de gases de efecto invernadero entre 1990 y 2050, y el aumento en el uso de fuentes de energía renovables para satisfacer el $10 \%$ de las necesidades energéticas para 2010. Por otro lado, la ley que acompañó la programación relacionada con la implementación del Foro del Medio Ambiente de Grenelle (2008) estableció objetivos, instrumentos y mecanismos de gobernanza para combatir el cambio climático (reducir el consumo de energía de los edificios existentes, realizar la renovación completa de 400.000 viv/año y aumentar el uso de las energías renovables). Tras los resultados de la conferencia anual sobre medioambiente de 2012, el presidente de la República anunció el 21 de marzo de 2013 la implementación de un Plan para la Renovación Energética del Habitat (Plan de Rénovation Énergétique de l'Habitat, $\mathrm{PREH}$ ). Este plan define una serie de medidas con el objetivo de incrementar la tasa de renovación de viviendas para alcanzar una reducción del $38 \%$ en el consumo de energía en el sector de la construcción para el 2020. Para conseguir estos objetivos, el PREH basa su estrategia en tres tipos de acciones: 1) apoyo a los hogares en la toma de decisiones para una renovación integral de alto rendimiento energético; 2) mejora de la financiación; 3) profesionalización del sector de la renovación energética.

En cumplimiento de la Directiva 2012/27/UE, Francia publicó en 2014 su primera Estrategia a largo plazo (Long-term renovation strategies, LTRS) para movilizar inversiones en la renovación del parque edificado, residencial y comercial, público y privado, que fue posteriormente revisada en 2017 y en 2020. Asimismo, en 2017 se definió el Plan Nacional de Acción en materia de Eficiencia Energética (Plan National d'Action en matière d'Efficacité Énergétique, PNAEE), marcando los objetivos de mejora de la Eficiencia Energética no sólo en el comportamiento del parque edificado, sino también en los sectores del transporte, la industria, la agricultura y el sector público.

Por su parte, la Ley $n^{\circ} 2015-992$ sobre la transición energética y de apoyo al crecimiento verde

degradadas y por un desequilibrio acentuado entre vivienda y empleo. 
(Loi de transition énergétique pour la croissance verte, LTECV) estableció también objetivos ambiciosos para el sector de la construcción. Esta cubre áreas clave de la transición energética y contiene muchas medidas, entre ellas la renovación del parque de edificios existente, de acuerdo con los estándares de "edificios de bajo consumo" y en particular, aprovechando obras integrales de gran envergadura para un alto rendimiento energético.

El Plan de Acción para la Calidad de la Construcción y la Transición Energética (Programme d'Action pour la qualité de la Construction et la Transition Énergétique, PACTE) fue lanzado a principios de 2015 por el Ministerio de Vivienda, Igualdad Territorial y Ruralidad, con el objetivo de apoyar a los profesionales de la construcción en el campo de la eficiencia energética, fortalecer la calidad en la construcción y reducir las barreras existentes en el sector. El programa busca capitalizar y mejorar el conocimiento en materia de eficiencia energética, promover soluciones técnicas de alta eficiencia y 3 ) continuar la modernización de los estándares de la industria en eficiencia energética.

En 2018, en desarrollo de los objetivos del Plan Climat (2017), y tras un intenso periodo de concertación, se publicó la primera versión del Plan de Rehabilitación Energética de Edificios (Plan de rénovation énergétique des bâtiments, PREB), desarrollado entre el Ministerio de Transición Ecológica e Inclusiva y el Ministerio de Cohesión Territorial, que ofrece herramientas para fomentar la rehabilitación energética de edificios, para alcanzar la neutralidad de carbono para 2050, al tiempo que se combate la pobreza energética.

\subsubsection{Política de vivienda}

Por último, es preciso mencionar la política sectorial de vivienda gestionada principalmente por la ANAH, dentro de la cual se gestiona y financia la política nacional para mejorar el stock de viviendas privadas existentes, incluyendo las acciones encaminadas a la mejora de la eficiencia energética. Otorga ayuda financiera a propietarios, ocupantes y arrendadores, así como a comunidades de propietarios, para realizar trabajos integrales de mejora de sus viviendas bajo ciertas condiciones (renta de los hogares, mejora del CEE, etc.).

Mediante el acuerdo firmado entre el Estado y ANAH, se creó el programa de apoyo financiero para la renovación térmica de viviendas privadas (JORF $n^{\circ} 0165$ du 20 juillet 2010), denominado Vivir Mejor (Habiter Mieux, HM). Su objetivo es resolver el problema de la inseguridad energética, que se estima que afecta a 3,8 millones de hogares en la actualidad. Se financia a través de los recursos presupuestarios de ANAH y el Fondo de Renovación Térmica (FART), para los cuales se asignaron inicialmente 483 millones de euros para el período 2010-2017 en el marco del Programa de Inversión Futura (Le Programme d'investissements d'avenir, PIA). EI programa se implementa a través de tres tipos de acciones: identificación de casos y diagnóstico, apoyo técnico, social y financiero y financiación de la ejecución del proyecto.

Aunque inicialmente el programa estaba dirigido a hogares precarios, en 2013 , se emitió un fallo que ajustaba los umbrales de ingresos (hasta rentas medias) para propietarios elegibles, otorgando así al $45 \%$ de los propietarios de viviendas

\begin{tabular}{|c|c|c|c|c|c|}
\hline \multirow{2}{*}{ Modalidad } & \multicolumn{2}{|c|}{ Ayudas } & \multirow{2}{*}{$\begin{array}{c}\text { Compromiso } \\
\text { acompañamiento }\end{array}$} & \multirow{2}{*}{$\begin{array}{c}\text { Empresas } \\
\text { RGE5 }^{5}\end{array}$} & \multirow{2}{*}{$\begin{array}{l}\text { Exigencia } \\
\text { energética }\end{array}$} \\
\hline & Proyecto & Ejecución & & & \\
\hline HM Sérénité ${ }^{6}$ & $\sqrt{ }$ & $\sqrt{ }$ & $\sqrt{ }$ & $\sqrt{ }$ & Alta \\
\hline HM Agilité & - & $\sqrt{ }$ & - & $\sqrt{ }$ & Media \\
\hline HM Copropriété ${ }^{7}$ & $\sqrt{ }$ & $\sqrt{ }$ & $\sqrt{ }$ & $\sqrt{ }$ & Alta \\
\hline
\end{tabular}

FIG. 2/ Modalidades del Programa Vivir Mejor.

\footnotetext{
${ }^{5}$ Garante ambiental reconocido (Reconnu Garant de l'Environnement, RGE): https://www.laprimeenergie.fr/lestravaux/les-travaux-deconomies-denergie/entreprise-rge

${ }^{6}$ Los esquemas HMi Sérénité y Agilité se pueden combinar con otros programas y asistencia financiera establecidos por el gobierno, en particular: CITE (crédito fiscal para la
}

transición energética); el préstamo ecológico a tasa cero (Eco-PTZ) bajo ciertas condiciones, y la ayuda local ofrecida por el Consejo Regional o el Consejo Departamental.

7 La modalidad HM Copropriété permite la financiación de comunidades de propietarios para proyectos que garanticen una reducción de energía de al menos un $35 \%$. 
en todo el país acceso a financiación (casi 7 millones de hogares). Todos los hogares elegibles para el apoyo del programa HM tienen derecho a las ayudas de la ANAH para la regeneración energética, a las que se añade una prima de hasta un $10 \%$ (varía dependiendo del nivel de precariedad). Desde 2018 el programa HM ha ampliado los tipos de ayuda en tres modalidades, dos específicas para las viviendas unifamiliares y una para edificios colectivos (FIG. 2).

Dos tercios de las subvenciones de ANAH se otorgan a través de programas implementados por las autoridades locales ${ }^{8}$, siendo todas ellas herramientas operativas. Es por esto, que el gran reto no es tanto la definición de herramientas, sino la mejora de los procesos y la gestión de las existentes para alcanzar los objetivos establecidos en las diferentes estrategias.

Para el 2020, la ANAH ha contado con un presupuesto reforzado de más de mil millones de euros para llevar a cabo sus misiones prioritarias: la lucha contra la pobreza energética, la revitalización de los cascos históricos de las ciudades medias, la recuperación de conjuntos degradados y la prevención de sus posibles problemas, y la lucha contra la vivienda no adaptada, estableciendo mejoras para asumir la pérdida de autonomía de una población cada vez más envejecida. Por su parte, la nueva Reglamentación Ambiental (RE2020) busca reducir la huella de carbono de la edificación buscando que sean construcciones térmicamente pasivas, o incluso energéticamente positivas (Bâtiment à Énergie Positive, BEPOS).

\subsubsection{Lucha contra la precariedad energética y la pobreza}

La Ley del 10 de julio de 2010 de compromiso nacional con el medio ambiente, conocida como la Ley Grenelle $2^{9}$, establece una definición legal de pobreza energética para el contexto francés:

\begin{abstract}
"Está en una situación de pobreza energética una persona que experimenta en su vivienda dificultades particulares para tener el suministro de energía necesario para satisfacer sus necesidades básicas debido a la insuficiencia de sus recursos o sus condiciones de vida"
\end{abstract}

La reducción del consumo energético de las viviendas es uno de los ejes de acción para luchar contra la pobreza energética. Tal y como

\footnotetext{
8 Programas como de Mejora de la Vivienda (OPAH), el Programa de Mejora Térmica de los Edificios (OPATB), el Programa de Mejora en un Sector Protegido, el Plan de Protección de los Edificios Degradados, Eliminación de la
}

se ha explicado en el punto anterior, la LTECV) establece entre sus objetivos la renovación de 500.000 hogares al año a partir de 2017 , de los cuales, al menos la mitad están ocupados por hogares de bajos ingresos. Con este objetivo se pretendía disminuir la pobreza energética en un $15 \%$ para el 2020.

Dentro de las acciones para facilitar el acceso a la financiación privada de los hogares con mayor precariedad, en abril de 2019 Fondo de Garantía de mejora de la Renovación Energética (FGRE), previsto en la LTECV, que tiene como objetivo facilitar el acceso financiero de los hogares de menor renta, contrarrestando la negativa de los bancos a financiar grupos de bajos recursos. EI FGRE proporcionaría una garantía del $75 \%$ de los préstamos ecológicos individuales de acuerdo con los umbrales de ingresos y favoreciendo una contragarantía que cubriría el $50 \%$ de los préstamos grupales.

Por último, cabe destacar otra medida implantada para reducir la pobreza energética, son los denominados Certificados de ahorro energético (CEE). El artículo 30 de la LTECV crea una nueva obligación de ahorrar energía en beneficio de los hogares que padecen pobreza energética. Esta obligación, que se impone a los proveedores de energía (combustibles, electricidad, gas, fuel oil, etc.), se puede cumplir implementando acciones de ahorro de energía en beneficio de los hogares cuyos ingresos son inferiores a un tope, o contribuyendo a programas de apoyo para estos hogares.

Además de luchar contra la pobreza energética a través de la mejora del comportamiento energético de los hogares, el gobierno francés también ha establecido medidas dirigidas al pago de la factura implementando desde tarifas sociales hasta cupones o cheques de energía.

\subsection{Instrumentos para la financiación de la rehabilitación energética}

\subsubsection{Ayudas a la rehabilitación de viviendas}

Las ayudas para la rehabilitación del parque edificado se dividen en dos grandes bloques (FIG. $3)$ : las ayudas fiscales, a través de la reducción

Vivienda Insalubre (RHI), las Operaciones de Restauración Inmobiliaria (ORI) y los Programas de Interés General (PIG) ${ }_{9}$ Referencia a la Ley Grenelle 2: https://www.senat.fr/dossier-legislatif/pil08-155.html 


\begin{tabular}{|c|c|}
\hline \multicolumn{2}{|c|}{ AYUDAS DIRECTAS } \\
\hline Préstamos & $\begin{array}{l}\text { - Préstamo de Interés ecológico de tasa cero (Eco-PTZ) } \\
\text { - Préstamo de Interés ecológico de tasa cero para vivienda social (Eco-PLS) }\end{array}$ \\
\hline Subsidios & $\begin{array}{l}\text { - Habiter Mieux (Sérénité, Agilité y Copropriété) } \\
\text { - Ayudas ANAH (Hogares rentas medias) } \\
\text { - Ayuda solidaria ecológica (ASE) }\end{array}$ \\
\hline \multicolumn{2}{|c|}{ AYUDAS INDIRECTAS } \\
\hline Fiscales & $\begin{array}{l}\text { - Crédito Fiscal de Transición de Energía (CITE) } \\
\text { - IVA reducido }{ }^{10} \\
\text { - Reducciones fiscales }\end{array}$ \\
\hline Otras & $\begin{array}{l}\text { - Certificados de eficiencia energética }{ }^{11} \\
\text { - Financiación colectiva }{ }^{12} \\
\text { - Financiación a terceros }\end{array}$ \\
\hline
\end{tabular}

Fuente: elaboración propia.

de impuestos y tasas, y las ayudas no fiscales, entre las que encontramos las ayudas directas a través de los diferentes programas de las agencias nacionales, regionales o locales, y las ayudas indirectas mediante préstamos ventajosos.

Las ayudas del PREH se complementan con otros fondos y ayudas complementarias como son los fondos FEDER y los Certificados de ahorro de energía (CEE).

Desde enero de 2020 se ha lanzado un nuevo programa renovación energética de las viviendas que busca simplificar los mecanismos y mejorar la coordinación (en particular alineando las condiciones de elegibilidad). Este programa se ha denominado MaPrimeRénov y está destinado principalmente a los hogares más pobres. Esta nueva ayuda fusiona el Crédito Fiscal de Transición de Energía (Crédit d'impôt pour la transition énergétique, CITE) $)^{14}$ por un lado, y la ayuda del programa HM Agilité, por el otro.

\subsubsection{Fondo nacional de garantía}

Tras la misión de la Depósitos y consignaciones de fondos (Caisse des Dépôts et Consignations, CDC) lanzada en marzo de 2013, el gobierno anunció el establecimiento de un fondo de garantía destinado especialmente a impulsar la oferta bancaria y alentar a los bancos a distribuir una nueva gama de Préstamos de "renovación energética" a particulares. Bajo esta perspectiva, se ha implementado un fondo de garantía específico el FGRE, parcialmente complementado por proveedores de energía, a escala nacional y que permita a los bancos cubrir

\footnotetext{
10 Reducción IVA: desde 2014 , la tasa reducida de $5.5 \%$ de IVA para la mejora de la eficiencia energética de alta calidad elegible para el crédito fiscal ha estado abierta a todos. Se ha mantenido una tasa del $10 \%$ para trabajos de mantenimiento y mejora.

${ }^{11}$ Certificados de eficiencia energética: creados en 2005 por la Ley POPE, se basan en la imposición de una obligación de ahorro de energía a los minoristas de energía por parte de las autoridades públicas. Por lo tanto, estos minoristas deben promover activamente la eficiencia energética entre los consumidores de energía, ya sean hogares, autoridades locales o profesionales. En la práctica, cada proveedor de energía debe proporcionar incentivos financieros para llevar a cabo la mejora de la eficiencia energética.

12 Financiación colectiva: la ley $n .^{\circ} 2012-387$ de 22 de marzo de 2012 relativa a la simplificación del marco legal y de los procedimientos administrativos, organizó los métodos de recurso al préstamo colectivo para comunidades de propietarias. La facilidad colectiva de préstamos ecológicos a tasa cero en copropiedad se creó mediante el decreto no, trabajos de renovación para mejorar el rendimiento energético de las viviendas antiguas.
}

\footnotetext{
${ }^{13}$ Financiación a terceros: en 2014 se comenzaron a desarrollar mecanismos de financiación innovadores, como la financiación de terceros, que consiste en ofrecer a cada copropietario una gama integrada de servicios (realización de obras y movilización de financiación para su realización) a cambio de pagos a lo largo plazo para facilitar la renovación térmica de la comunidad, siempre bajo el impulso de las autoridades locales que pueden actuar a través de empresas intermediarias.

${ }_{14}$ Crédito Fiscal de Transición de Energía (CITE) permite deducir de los impuestos entre un $15 \%$ ( $25 \%$ en conjuntos) y $30 \%$ de los gastos incurridos en el proyecto de rehabilitación energética sujetos a impuestos comunes (no puede exceder de $8.000 €$ para una persona soltera y $16.000 €$ para una pareja sin hijos). Además de incentivar, el objetivo de este dispositivo es respaldar las tecnologías emergentes y las innovaciones más eficientes. Cite web: https://www. cohesion-territoires.gouv.fr/credit-dimpot-pour-la-transitionenergetique-cite
} 
parcialmente sus primeras pérdidas. El objetivo es permitir una extensión de la duración de los préstamos para obras y, al optimizar las condiciones para refinanciar estos préstamos, impactando en una reducción en el costo de las obras. Su aplicación requiere una garantía de propiedad social de la vivienda y la firma de acuerdos de conformidad según un modelo definido por el decreto de 14 de marzo de 2019, entre el Estado y la Sociedad Gestora de Fondos y de la Garantía de propiedad social de la vivienda, por una parte, y entre el Estado, dicha Sociedad y las entidades de crédito, por otra.

\subsubsection{Ayudas locales}

Recientemente, algunas autoridades locales han lanzado varias iniciativas destinadas a desarrollar una gama completa de asesoramiento para los hogares con disposición. para facilitar la financiación de los trabajos de rehabilitación. En una primera familia, llamada "tercero de confianza", el sistema público local asume las funciones de orientación, apoyo a los hogares en todas las fases (durante el diseño, para la finalización de las obras y posteriormente, para monitorear el consumo), mientras realiza acuerdos con el sector bancario para ofrecer financiación más ventajosa. Son posibles diferentes esquemas y se están probando en los territorios, en diferentes etapas de avance.

Sobre la base de las primeras experiencias en Francia de operadores de la renovación energética en la edificación, la Región de Picardía, acompañada por la Dirección Regional de ADEME, decidió en septiembre de 2013 implementar una operación piloto llamada "Servicio Público de Eficiencia energética” (SPEE). Este servicio público permite combinar una forma de "servicio integrado" que acompaña a los hogares en todos los aspectos de su proyecto de renovación (definición, financiación y ejecución). La región de lle de France también ha establecido un servicio público, llevado a cabo por SEM Energies Posit'if, para que las personas puedan recibir asesoramiento y apoyo financiero para la ejecución de los trabajos de rehabilitación energética. Otras regiones, como Bretaña o Nord-Pas de Calais, han decidido establecer un servicio integrado para intervenir en su parque residencial. Destacar también que algunas autoridades locales han tomado recientemente la iniciativa de crear operadores públicos dedicados a la rehabilitación del patrimonio público, como el SPL OSER en la región de Rhône-Alpes.

\subsubsection{Fiscalidad verde}

Algunas obras pueden también recibir ayudas fiscales (préstamo impuesto para servicios de ayuda a las personas, equipamientos para personas mayores o con discapacidad, préstamo impuesto desarrollo sostenible, eco-préstamo sin intereses financiado por los bancos a través de préstamos de impuestos, posibilidad de exención de impuestos sobre bienes inmobiliarios).

En Francia existen diversos beneficios fiscales a la rehabilitación de viviendas:

- IVA reducido (5,5\%) para todo tipo de obras en edificios de viviendas de más de 2 años.

- Reducción de impuestos para gastos que favorecen el acondicionamiento para las personas mayores y con discapacidad.

- Deducción fiscal sobre todas las obras de mejora realizadas por los arrendadores.

- Exención de impuestos inmobiliarios para la rehabilitación de las viviendas sociales.

- Desgravación de impuestos inmobiliarios en obras de accesibilidad y ahorro energético.

\subsection{Instrumentos para la movilización de agentes}

\subsubsection{Puntos de información sobre rehabilitación (pris)}

Para guiar a los propietarios para realizar trabajos de renovación energética, el gobierno francés ha establecido un servicio público de asesoramiento técnico y administrativo, independiente y gratuito.

Este servicio público se materializa en dos canales:

\section{- Plataforma telefónica nacional.}

- Sitio web nacional (www.renovation-info-service.gouv.fr) que remite a las personas interesadas, según su situación y sus necesidades, a un único punto de recepción (el más adecuado y más cercano a casa), denominado Punto de Servicio de Información sobre Renovación (Point Rénovation Info Service, PRIS).

En la siguiente figura (FIG. 4) se muestra el procedimiento y estructura de los PRIS. 


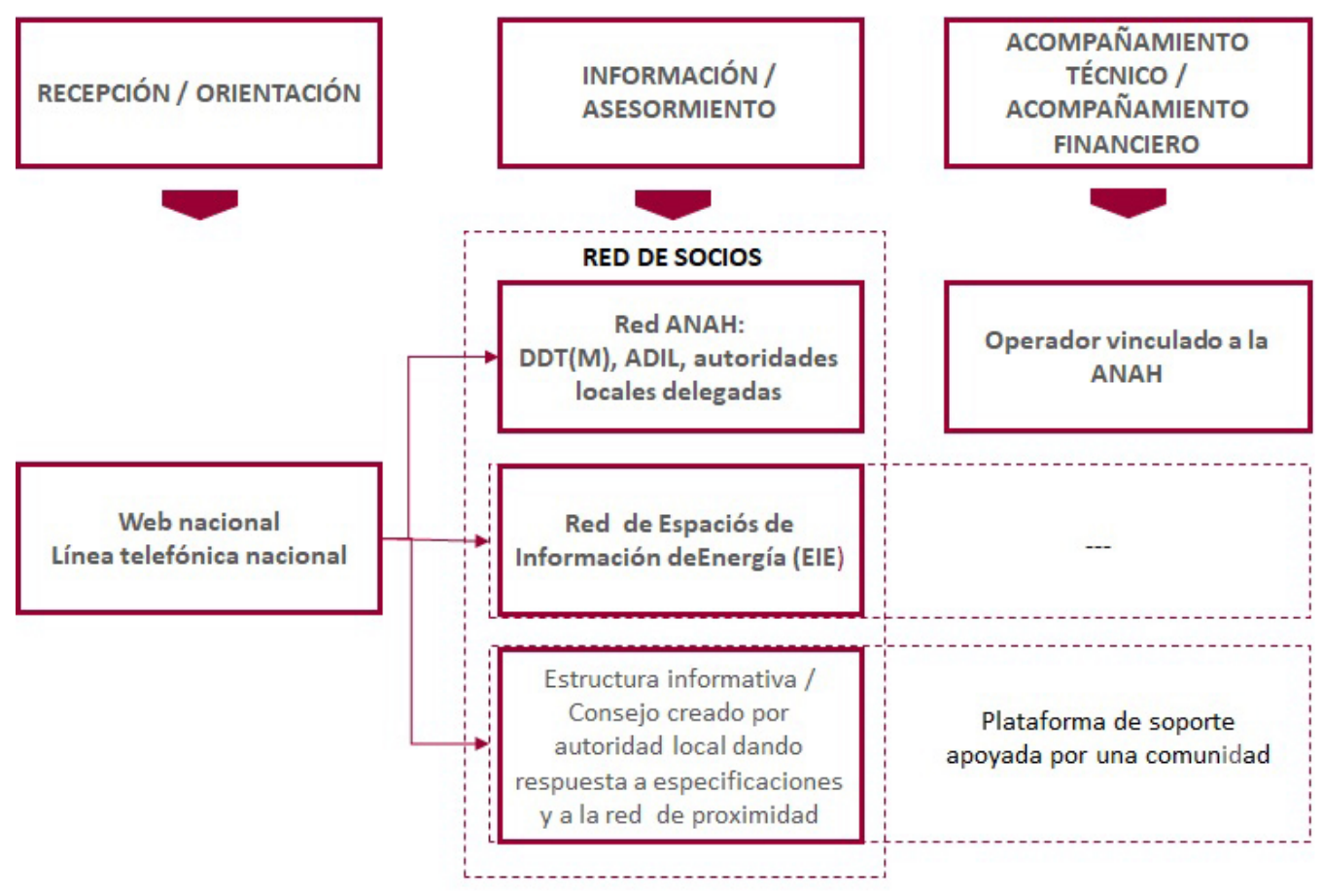

FIG. 4/ Procedimiento y estructura de los PRIS.

Fuente: elaboración propia a partir de www.renovation-info-service.gouv.fr/accessibilite

Más de 450 PRIS están presentes en todo el país y brindan información y asesoramiento gratuitos, tanto técnico (asesoramiento sobre la elección del trabajo a realizar, ofertas de profesionales) como financieros (ayuda y métodos de financiación). Estos puntos dependen de las agencias de información de vivienda departamentales (Agences Départementales d'Informations sur le Logement, ADIL) o de las Direcciones departamentales para territorios y el mar (Directions Départementales des Territoires et de la Mer, DDT-M), en el caso de las ayudas públicas elegibles de la Anah, y de los Espacios de información energética (Espaces Info Energie, EIA dentro del programa FAIRE $^{15}$ ) de la ADEME, o mostradores y plataformas establecidos por las autoridades locales $^{16}$, Por ejemplo, en la región de París se desarrolló la herramienta "Co-coach" de la Agencia de Clima de París (EIE) para apoyar a las comunidades a lo largo de las etapas de la renovación: financiación a movilizar, los trabajos a realizar y su seguimiento, etc.

\footnotetext{
15 https://www.faire.gouv.fr/pourquoi-faire

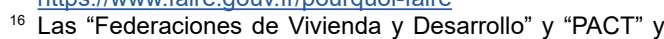
"ARIM" implantadas en todo el territorio desempeñan
}

\subsubsection{Movilización de colectivos locales}

Tal y como se indica en la LTRS 2014, para sensibilizar lo más posible a los hogares es necesaria la participación de las autoridades locales en la implementación de acciones a favor de la renovación energética de las viviendas, ya que la experiencia ha demostrado que es más probable que las personas contacten con los servicios locales para recibir asesoramiento sobre la gestión de su vivienda. Muchas autoridades locales ya han llevado a cabo iniciativas, que van desde la difusión de información y la sensibilización de todos los agentes, hasta el apoyo para llevar a cabo las obras, incluido el desarrollo de herramientas financieras y la movilización de empresas y profesionales del sector.

Por otro lado, el METL y el MEDDE lanzaron una convocatoria de premios para "iniciativas locales para la renovación energética” en mayo

también un papel de información y asesoramiento a los particulares. 
de 2013, con el fin de identificar y promover trabajos de renovación energética en viviendas, ya sea cuantitativa o cualitativamente. Entre los proyectos premiados se incluyeron diferentes experiencias que ponen en valor aspectos como la gestión a través de ventanilla única, la introducción de esquemas financieros como la financiación a terceros u otros aspectos como la lucha contra la pobreza energética y el impulso de la renovación energética, así como el apoyo al sector industrial de la construcción ecológica.

Entre las principales herramientas de comunicación y sensibilización ya se han mencionado los PRIS y los EIE, pero también habría que incidir en las siguientes figuras.

- Embajadores de la regeneración energética: se crean para apoyar a los hogares más vulnerables y aislados. Son reclutados por parte de las autoridades locales o del PRIS, en asociación con la ANAH. Su misión es identificar de manera proactiva ese tipo de hogares y ayudar a difundir información.

- Partenariados con asociaciones de profesionales: ADEME realiza trabajos de proximidad y facilitación en asociación con comunidades, asociaciones, oficinas de diseño, empresas, organismos consulares y organizaciones profesionales. Este trabajo toma la forma del desarrollo de herramientas, métodos y procedimientos a través de contratos con territorios.

\subsubsection{Mejoras y profesionalización de la industria}

El PREH incluye también como aspecto prioritario la profesionalización del sector de la renovación energética para garantizar la calidad de los trabajaos y mejorar las capacidades de las empresas y los profesionales. El impacto del plan en el número de empleos directos e indirectos creados o mantenidos se estimó en 75.000.

La profesionalización del sector de la renovación energética pasa por varios ejes:

- En el marco del programa RAGE ${ }^{17}$ Actualización de los centros de formación profesional

\footnotetext{
17 Programa RAGE - Règles de l'art Grenelle environnement: tiene como objetivo revisar todas las reglas de construcción para ahorrar energía en el edificio y reducir las emisiones de gases de efecto invernadero.

18 Programa FeeBAT (Capacitación de profesionales en ahorro de energía en edificios) contribuye a apoyar el desarrollo de habilidades de los profesionales de la construcción en el campo de la eficiencia energética. Este programa está
}

para dar respuesta a los desafíos de la renovación energética.

- Formación masiva de empleados de empresas de construcción y artesanos, en particular a través del programa FEEBat ${ }^{18}$.

- Reconocimiento como empresas garantes del medio ambiente (Reconnu Garant de l'Environnement, $\mathrm{RGE}^{5}$ ): estos sellos de calidad se entregan a las empresas excelentes algún campo de trabajo relacionado con la mejora del medio ambiente. Determinadas ayudas están condicionadas a la contratación de empresas con RGE.

\subsection{Aplicabilidad en España}

La estructura administrativa de Francia, con un alto grado de centralidad, hace difícil la trasposición a España de algunas de las medidas analizadas. Aun así, podríamos apuntar algunos aspectos relevantes que sí podrían trasladarse a nuestro contexto.

A. Desarrollo e implementación de la Ley de Transición energética y crecimiento verde (LTECV 2015): La LTECV cubrió las diferentes áreas clave de la transición energética y contiene muchas medidas, entre ellas la renovación del parque de edificios existente. Estas medidas referidas a la mejora del rendimiento energético del entorno construido estuvieron estrechamente ligadas al desarrollo anterior de la LTRS 2014. Esta integración de la estrategia con el marco legislativo en materia de energía y cambio climático ha facilitado una dotación económica más estable además de todo el desarrollo reglamentario y de instrumentos que lo acompañó.

En el contexto español nos encontramos en un momento similar, con la aprobación de la Ley de Cambio Climático y Transición Energética. Parece por tanto un momento propicio para el desarrollo una estrategia energética integral y coordinada que permita alcanzar los objetivos 2030 y 2050.

B. Diseño y gestión integral de las ayudas para el ahorro energético y lucha contra la pobreza

financiado por Électricité de France (EDF) a través de Certificados de Ahorro de Energía (CEE) y fondos de educación continua de recaudación de fondos corporativos. El nuevo acuerdo 2018-2020 marca una importante evolución del sistema FEE Bat. y está totalmente en línea con el plan de renovación anunciado el 26 de abril de 2018 por los Ministerios de Transición Solidaria Ecológica y Cohesión Territorial. Referencia: http://www.feebat.org/ 
energética a escala municipal (y de barrio): aunque pueda darse el caso de la existencia de planes y programas sectoriales con objetivos y acciones propias (como es el caso del programa Habiter Mieux y el PREH), es importante contar con una agencia (como la ANAH) que gestione las ayudas a través de una ventanilla única. Para el caso español, y dada la estructura territorial y competencial del Estado de las Autonomías, esta ventanilla única quedaría a nivel autonómico, aunque sería recomendable contar con una cierta homogeneidad para todo el territorio. El desarrollo de proyectos a nivel de conjunto edificatorio (vecindario y/o barrio) es fundamental para alcanzar los niveles de rehabilitación requeridos.

C. Comunicación y sensibilización unitaria: en Francia se ha creado un punto de contacto nacional (web y telefónico) dirigido a residentes (propietarios o inquilinos), empresas e instituciones públicas. Desde ese punto focal se derivan las consultas a los puntos de contacto regionales, facilitando la comunicación de la información. Al igual que en el punto anterior la aplicabilidad al caso español depende de la realidad territorial y competencial.

D. Ayudas variables según la mejora energética y para conjuntos edificados: cuanto más integral sea el proyecto y mejor rendimiento energético alcance mayor cuantía de la subvención se podrá obtener. La agregación de la demanda mediante la intervención en conjuntos edificados también cuenta con una mejora de las ayudas, tanto para la rehabilitación como para la gestión.

E. Profesionalización: todas las medidas aplicadas para la mejora de los profesionales del sector son perfectamente aplicables al caso español (actualización de los centros de formación profesional, registro de empresas con sello de garantía ambiental, etc.). Para optar a determinadas ayudas se establece como requisito el contratar profesionales con sello RGE.

F. Creación de un fondo de garantía nacional: facilitando el acceso a los préstamos, tanto a particulares (mediante la figura de avalista) como a empresas públicas, o permitiendo una extensión de la duración de los préstamos para obras al optimizar las condiciones para refinanciar estos préstamos.

G. Beneficios fiscales: el IVA reducido, reducciones del IRPF y otros.

\section{Políticas e instrumentos de fomento de la rehabilitación en Alemania}

\author{
3.1. Visión global de las políticas \\ de rehabilitación en Alemania
}

En el seno de la UE, Alemania es un país referente en la política industrial y tecnológica centrada en la energía, y la movilidad como ejes clave para la transición ecológica del país. Desde la década de 1970, tras la crisis del petróleo acontecida en esa década, el país comenzó a desarrollar políticas de transición energética y ecológica, entre las cuales se encuentra la rehabilitación del parque construido. Según el EU Building Stock Observatory, en 2014 se renovaban en profundidad aproximadamente el $1,49 \%$ de los edificios de Alemania, siendo el segundo país europeo en tasa de renovaciones tras Francia ${ }^{1}$. Las políticas de rehabilitación están muy ligadas a las políticas de transición energética, aunque también forman parte de concepto más integrales de regeneración urbana a escala local.

\subsubsection{Política de transición energética}

Desde la década de 1970 Alemania ha desarrollado una amplia gama de instrumentos y herramientas para aumentar la eficiencia energética, incluso antes de que se adoptara la Directiva de Eficiencia Energética europea. Cuenta con una política consolidada en este campo, logrando incluso el desacoplamiento del consumo de energía del desarrollo económico (PIB), siendo el ahorro energético a través de la eficiencia energética y el uso intensivo de las energías renovables algunos de los pilares fundamentales de la transición energética y ecológica en Alemania. En 2010, el Ministerio Federal Alemán de Medio Ambiente, Protección de la Naturaleza, Construcción y Seguridad Nuclear (BundesministeriumfürBildungundForschung, $\mathrm{BMU}$ ) y el Ministerio Federal Alemán de Asuntos Económicos y Energía (BundesministeriumfürErnährungundLandwirtschaft, BMWi) publicaron el documento titulado Política de Transición Energética (Energiewend) que definía el futuro de política energética hasta 2050. Entre sus prioridades estaban:

- El aumento de las energías renovables, mediante el desarrollo de una planificación y un marco regulatorio adecuado integrada en la política de Cambio Climático. 


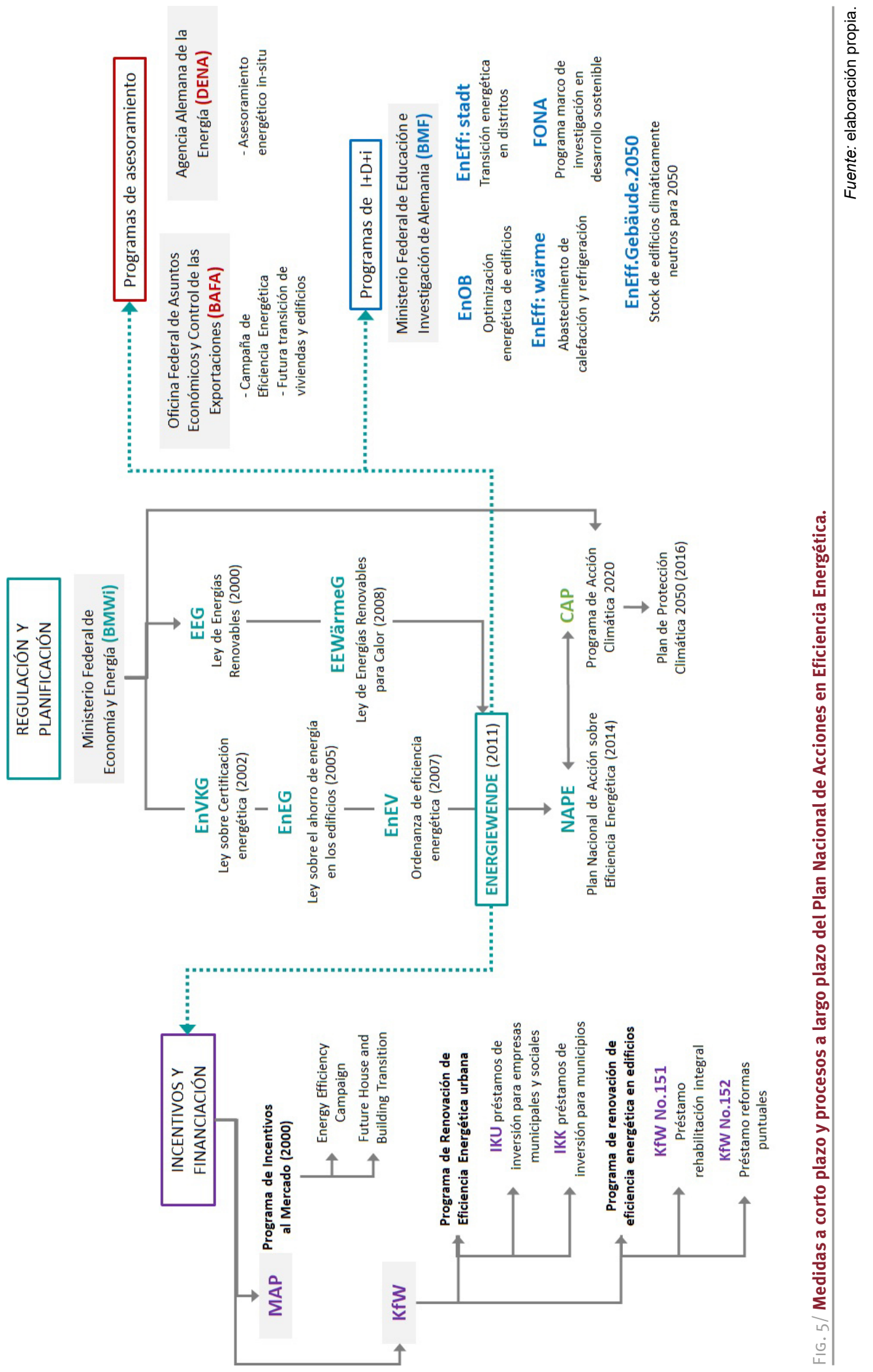


- El fomento del I+D+i para incrementar el desarrollo tecnológico en diferentes programas como el de redes de distribución de calor o el de optimización energética de la edificación, entre otros.

- El desarrollo de programas de asesoramiento y sensibilización de los diferentes agentes.

- Implementación de un marco financiero estable y adecuado a los retos planteados.

Estos cuatro ámbitos prioritarios, se venían desarrollando en las diferentes políticas sectoriales y a través de la Energiewend se busca consolidar la integración y coordinación entre todas ellas (FIG. 5).

En términos sociales, la Política de Transición Energética es un proyecto que ha requerido una enorme participación ciudadana y la implementación de su visión está generando cambios en la vida diaria de la ciudadanía, las empresas y en la economía en general. También ha requerido profundos cambios sociales, no solo en el área de la energía, sino también en la arquitectura, la planificación urbana, la agricultura, etc. Ciento ochenta universidades y escuelas politécnicas trabajaron en el programa de transición energética entre 2011 y 2013; el Ministerio de Investigación tenía un fondo para subvenciones relacionadas con este programa de 2.000 millones de euros.

\subsubsection{Legislación sobre ahorro energético en la edificación}

En Alemania, cerca del $40 \%$ de toda la energía se consume en edificios, principalmente en calefacción. En 2005, se estableció la Ley sobre el ahorro de energía en los edificios (Energieeinsparungsgesetz EnEG) que se centra en promover la eficiencia energética en viviendas y edificios terciarios y de la cual derivó la primera Ordenanza de Conservación de Energía (Energieeinsparverordnung EnEV). En relación con la construcción de nuevos edificios, en 1990, la transición energética alemana inició el desarrollo del estándar Casa Pasiva de alta eficiencia (Passivhaus) para aumentar la eficiencia energética en los edificios.

Posteriormente, la regulación en materia de ahorro energético que traspuso los nuevos requisitos de la EPBD (Directiva 2010/31/UE) fijó también los requisitos energéticos mínimos para el desarrollo de Edificios de Energía Casi Nula (nZEB), entrando en vigor para todos los edificios nuevos a partir del 1 de enero de 2016. Se implementaron además los métodos de cálculo para incluir las condiciones límite obligatorias (edificio de referencia) para su aplicación tanto en los edificios residenciales como en los no residenciales.

\subsubsection{Plan Nacional de Acción sobre Eficiencia Energética}

Alineado con la Política de Transición Energética, el Plan deAcción Nacional de Eficiencia Energética (NationalerAktionsplanEnergieeffizienz, PNAEE) de 2014, incluye, en relación al PNAEE 2011, medidas políticas nuevas y más desarrolladas para aumentar la eficiencia energética en edificios residenciales, industriales y edificios terciarios. El plan se estructura según los siguientes ejes de acción:

- Renovación energética de edificios: en octubre de 2015, el Gobierno Federal adoptó la Estrategia de Eficiencia Energética para Edificios (LTRS 2014. La estrategia recoge las principales acciones para la transición energética en el sector de la edificación y también sirvió de base para el capítulo sobre edificios del Plan de Protección Climática 2050 adoptado por el Gobierno Federal en 2016. Entre los instrumentos que desarrolla la estrategia está la Ley de Generación de Calor con Energía Renovable (ErneuerbareEnergien-Wärmegesetz, EEWärmeG) y la Ordenanza sobre Ahorro de Energía.

- Monitorización / Plataformas de transición energética: A través de un informe anual se describe y evalúa el estado de implementación de la transición energética en Alemania. También es importante considerar el papel de la sociedad en la elaboración de políticas, por eso el Ministerio Federal de Economía y Energía (BMWi) ha creado cinco plataformas o grupos de trabajo para la transición energética: mercado de energía, eficiencia, redes eléctricas, edificios e investigación e innovación. Por otro lado, el Ministerio Federal de Educación e Investigación de Alemania (BMBF) ha activado otra plataforma para el diálogo llamada Foro de Investigación para la Transición Energética, que incluye a las partes interesadas de la industria energética y representantes de instituciones políticas y académicas, la industria y la sociedad civil. 


\subsubsection{Las estrategias a largo plazo para movilizar inversiones en la re- novación del parque nacional de edificios para uso residencial y ter- ciario $(2014,2017)$}

La Estrategia de Eficiencia Energética para Edificios se define como una estrategia de aprendizaje dinámica, y el Gobierno Federal ha iniciado medidas adicionales y desplegado una combinación integral de instrumentos que incluyen la provisión de información, asesoramiento y financiación, la imposición de nuevos requisitos y la implementación de proyectos de investigación para alentar a los propietarios, el sector inmobiliario, las empresas y los municipios, a tomar decisiones de inversión que apoyen la transición energética.

La LTRS toma como base la Política de Transición Energética, así como los objetivos definidos por el PNAE 2014. Entre estos objetivos está el obtener el apoyo y la aceptación de todos los actores sociales para trabajar de manera coordinada en la mejora de la eficiencia energética, destacando las posibilidades y oportunidades para cada uno de ellos, y haciendo ver que el compromiso con la eficiencia energética es algo positivo. Basado en una mezcla de consultoría, comunicación e información sobre medidas de eficiencia valiosas, financiación y estándares para nuevas instalaciones, la estrategia contiene un conjunto de instrumentos que incentivan la eficiencia energética al tiempo que allana el camino para aprovechar el enorme potencial de la transición energética para la industria en el uso de energías renovables.

El gobierno federal tiene como objetivo reducir las emisiones de $\mathrm{CO}_{2}$ en los edificios en un $40 \%$ en comparación con 1990 para 2020. Para 2050, las emisiones de $\mathrm{CO}_{2}$ se reducirán entre un $80 \%$ y un $95 \%$. Para alcanzar estos objetivos globales, el gobierno se compromete a duplicar la tasa de renovación anual del $1 \%$ al $2 \%$. Se espera que las mayores contribuciones al ahoro de energía y $\mathrm{CO}_{2}$ vengan de un esquema de licitación competitivo recientemente introducido para la eficiencia energética y el establecimiento de hasta 500 redes de eficiencia energética en la industria.

El concepto de renovación rentable, incluido en la LTRS 2017, tiene en cuenta las barreras existentes en la mejora de eficiencia energética, la integración de energías renovables y la estructura de propiedad existente del parque inmobiliario, que se resumen a continuación:
- Eficiencia energética: los cálculos actuales indican que será posible reducir el consumo de energía final a aproximadamente 1600PJ para 2050 como resultado de las medidas de eficiencia energética. Esto corresponde a una reducción del $54 \%$ en el consumo final de energía en comparación con 2008. Los ejemplos de las restricciones que se aplican a este respecto incluyen las opciones para aislamiento de envolvente y aumento de su eficiencia energética, así como la introducción o mejora de los sistemas de redes de calor.

- Energías renovables: sobre la base de los cálculos actuales, el potencial total de las energías renovables que podría ser utilizado para el sector de la construcción en 2050 , incluidas las redes de calor y la electricidad de fuentes de energía renovable, se estima entre de 1400 PJ y 1800 PJ. Esto supone un $40 \%$ y $50 \%$ del consumo final de energía actual y (dependiendo de las mejoras en eficiencia) una participación de aproximadamente $60 \%$ a $70 \%$ de las energías renovables en 2050 .

- Estructura de tenencia del parque de viviendas: la estructura de tenencia del parque de viviendas (alrededor de 18 millones de hogares en alquiler frente a poco menos de 10 millones de hogares en propiedad) representa el tercer obstáculo hacia la consecución de un parque edificado energéticamente neutro.

En 2017, el Gobierno Federal lanzó la Hoja de ruta para renovaciones a medida con el objetivo de acercar a los propietarios el concepto de renovación rentable.

\subsection{Instrumentos para la financiación de la rehabilitación energética}

Las ayudas para la rehabilitación del parque edificado se dividen en dos grandes bloques (FIG. 6): las ayudas fiscales, a través de la reducción de impuestos y tasas, y las ayudas no fiscales entre las que encontramos las ayudas directas a través de los diferentes programas de las agencias nacionales, regionales o locales y las ayudas indirectas mediante préstamos ventajosos.

Para entender el conjunto de las ayudas, en la siguiente tabla se listan los instrumentos existentes, que se explican más detalladamente a lo largo del capítulo. 


\begin{tabular}{|c|c|}
\hline \multicolumn{2}{|c|}{ Ayudas directas } \\
\hline Préstamos & $\begin{array}{l}\text { - Programa MAP PYMEs de préstamos de bajo interés } \\
\text { - Programa KfW Renovación energética de préstamos de bajo interés (Préstamo } \\
\text { N. } .^{\circ} 151 \text { y Préstamo N.․ 152) } \\
\text { - KfW para la Rehabilitación de Eficiencia Energética urbana: préstamos de } \\
\text { inversión para municipios (IKK) y empresas sociales (IKU) }\end{array}$ \\
\hline Subsidios & $\begin{array}{l}\text { - Programa MAP subvención particulares } \\
\text { - Programa MAP PYMEs subvención reembolsable } \\
\text { - Programa } \mathrm{KfW} \mathrm{CO}_{2} \text { rehabilitación energética con ayuda directa } \\
\text { - KfW para la Rehabilitación de Eficiencia Energética urbana: Programa de } \\
\text { financiación de optimización de calefacción }\end{array}$ \\
\hline \multicolumn{2}{|c|}{ Ayudas indirectas } \\
\hline Fiscales & $\begin{array}{l}\text { - Desgravación fiscal por los servicios prestados por constructores y profesionales } \\
\text { - Reducciones fiscales }\end{array}$ \\
\hline Otras & $\begin{array}{l}\text { - EnEff.Building.2050 } \\
\text { - Programa de financiación para redes de calor de cuarta generación }\end{array}$ \\
\hline
\end{tabular}

Fuente: elaboración propia.

\subsubsection{Programa MAP de incentivos de mercado}

El Programa de Incentivos al Mercado (Marktanreizprogramm, MAP) es un programa de financiación del Ministerio Federal de Asuntos Económicos y Energía que ofrece incentivos para hacer un mayor uso de las energías renovables en la generación de calor en todos los ámbitos (hogares, empresas, municipios, etc.). El Estado financia el reemplazo de sistemas de calefacción antiguos con una instalación solar térmica eficiente, instalación de biomasa o bomba de calor. También proporciona financiación para establecer redes de calor y unidades de almacenamiento de calor.

Hay dos tipos de financiación disponibles:

- Subvenciones de la Oficina Federal deAsuntos Económicos y Control de Exportaciones (BAFA), para particulares: para instalaciones pequeñas en hogares y empresas privadas. Estos incluyen colectores solares térmicos en la azotea, sistemas de calefacción de biomasa en el sótano y sondas geotérmicas eficientes para bomba de calor.

- $\quad 35 \%$ de la inversión con el cambio a radiadores eléctricos que funcionen completamente con energía renovable.

- $\quad 25 \%$ de la inversión con el cambio a calefacción híbrida de gas con una cuota renovable, además sobre la integración de la energía solar térmica se incrementa hasta un $30 \%$;
- $20 \%$ de la inversión con el cambio a calderas de condensación de gas que están preparadas para la posterior integración de las energías renovables.

- Préstamos a bajo interés y subvenciones de reembolso del KfW, para PYMES: para sistemas más grandes, particularmente aquellos utilizados en un entorno comercial (lavanderías, hoteles, etc.) o empresas municipales que están invirtiendo en instalaciones de cogeneración de biomasa y redes de calefacción diseñadas para funcionar con energías renovables.

- Subvenciones reembolsables:

- De hasta el $40 \%$ del total de la inversión por la instalación de un sistema de colector solar en el complejo de oficinas.

- De hasta $100.000 €$ para bombas de calor y plantas de biomasa.

- De hasta $1 \mathrm{M} €$ para sistemas de almacenamiento de calor.

\subsubsection{Programa de KfW para la renovación energética de edificios}

El Banco para la Reconstrucción de Alemania (Kreditanstalt für Wiederaufbau, KfW) es la institución que gestiona el apoyo financiero a los propietarios que quieren rehabilitar su vivienda para que sea energéticamente más eficiente. Dentro 
del programa se toma como referencia el concepto de Vivienda Eficiente KfW (VE KfW) en referencia a una vivienda que cumple los estándares utilizados para clasificar las necesidades de energía de un edificio de nueva construcción o edificio de referencia. La cantidad de fondos que obtendrá cada propietario dependerá en parte del estándar de eficiencia que se quiera alcanzar tras la rehabilitación (FIG. 7).

El estándar VE KfW se define según dos parámetros: las necesidades anuales de energía del edificio y la cantidad de calor que se permite escapar a través de ventanas y paredes exteriores mal aisladas. Para cumplir con el estándar más alto de eficiencia energética, generalmente se requieren rehabilitaciones integrales incluyendo la renovación de los sistemas de calefacción, el aislamiento térmico y el reemplazo de ventanas.

Según el EnEV se establece como vivienda de referencia la VE KfW 100. Pero es posible construir casas que sean aún más eficientes energéticamente, esto es:

- VE KFW 100. cumple con todos los requisitos mínimos legales.

- VE KfW 70 no necesita más del $70 \%$ de la energía que necesitaría una VE 100.

- VE KfW 55 necesita menos que la anterior: apenas el 55\% de lo que necesita la VE 100.

$\mathrm{KfW}$ ha definido seis niveles de apoyo para la renovación de edificios en función del nivel de eficiencia energética que se alcance respecto al edificio o vivienda de referencia. El mejor estándar (55) recibe la ayuda más alta.

El programa cuenta con dos tipos de préstamos:
- Préstamo No. 151: para una renovación integral del edificio a una VE KfW. La cuantía máxima del préstamo es de $120.000 €$ euros, con un plazo de amortización de hasta 30 años y un subsidio de reembolso máximo del $40 \%$ del total del préstamo (48.000 €).

- Préstamo No. 152: para medidas individuales. La cuantía máxima del préstamo es de $50.000 €$, con un plazo de amortización de hasta 30 años y un subsidio de reembolso máximo del $20 \%$ del total del préstamo $(10.000 €)$.

El propósito de este programa no es sólo promover el ahorro de energía, sino también limitar la carga, impuesta a los inquilinos y propietarios más vulnerables, de los costos de la renovación. Destacar, que los hogares de bajos ingresos reciben ayuda financiera directa para los gastos de mejora de su vivienda y calefacción a través de la seguridad social y como parte de la asignación del subsidio de desempleo. El Gobierno Federal también garantiza que estos hogares reciban asesoramiento gratuito en alguna de las 650 oficinas de atención al consumidor, en las oficinas municipales, o mediante controles de edificios in situ realizados por consultores de energía.

\subsubsection{Programa KfW para la rehabilitación de eficiencia energética urbana}

El Ministerio Federal de Transporte, Construcción y Asuntos Urbanos de Alemania (BMVBS) y KfW presentaron en 2011, con una fase piloto, el

\begin{tabular}{lccc}
\hline Viviendas de referencia & $\begin{array}{c}\text { Demanda } \\
\text { energía } \\
\text { primaria }\end{array}$ & $\begin{array}{c}\text { Pérdida calor por } \\
\text { transmisión } \\
\text { específica }\end{array}$ & $\begin{array}{c}\text { Subsidio } \\
\text { reembolsable }\end{array}$ \\
\hline Vivienda Eficiente KfW 55 & $55 \%$ & $70 \%$ & $27,5 \%$ \\
inversión
\end{tabular}

FIG. 7 / Financiación KfW, dentro del programa $\mathrm{KfW} \mathrm{CO}_{2}$ según el estándar de Vivienda Eficiente como edificio de referencia.

Fuente: elaboración propia. 
Programa de subvenciones para Rehabilitación de la Eficiencia Energética Urbana como un componente de la Política de Transición Energética del gobierno federal alemán, incluido en el Fondo de Energía y Clima, y en estrecha cooperación con los estados federales, para alcanzar los objetivos de cambio climático para 2020 y 2050. El programa está dirigido a los municipios ${ }^{19}$ que desean mejorar la eficiencia energética en sus barrios ${ }^{20}$, para subvencionar proyectos de rehabilitación urbana integrales que respondan no solo a los aspectos energéticos o climáticos, sino también a aspectos sociales como puede ser el envejecimiento. El programa está diseñado para lograr sinergias en los barrios a través de un proceso de rehabilitación que va más allá de los edificios individuales para intervenir en áreas urbanas más amplias, integrando diferentes medidas de rehabilitación urbana para la mejora del comportamiento energético de toda el área. El programa consta de dos componentes:

- Subvención para la Regeneración Urbana Energética: se subvencionan proyectos integrados a nivel de barrio que incluyan medidas de rehabilitación energética eficiente de edificios e infraestructuras, en particular para calefacción y refrigeración. Para obtener la subvención, los municipios interesados deberán revisar de manera particular los objetivos energéticos de la ciudad donde se vayan a implementar los proyectos, como base central para la toma de decisiones y como ayuda a la planificación de inversiones para la reducción de emisiones de $\mathrm{CO}_{2}$ a corto, medio y largo plazo. Los aspectos identificados como clave para los proyectos son: antigüedad de la edificación, eliminación de barreras arquitectónicas, estado de las infraestructuras urbanas, estructura social del distrito, e impactos en las personas.

- Costes para gestión y coordinación: el programa incluye subvenciones para los costes de personal y materiales para la gestión (costes elegibles por un período de entre 3 y 5 años). Esto incluye:

- Iniciar los procesos individuales de cada edificio como paso previo a la cooperación global y la creación de redes de actores.

- Crear un punto de contacto para información sobre financiación y gestión.

\footnotetext{
19 A la promoción también pueden optar empresas de servicios públicos municipales, asociaciones de vivienda y propietarios privados o asociaciones de propietarios de vecindarios que tengan interés en mejorar la eficiencia energética de sus vecindarios.
}

- Se recomienda que las tareas de gestión y mediación se realicen por una o más personas de diferentes disciplinas (rehabilitación, energía, desarrollo urbano, vivienda o bienes inmuebles, renovación urbana, comunicación social, etc.).

La subvención para ambos componentes asciende al $65 \%$ del coste total. El monto máximo de la subvención para el equipo de gestión (para un periodo generalmente de un máximo de 3 años) asciende a un total de hasta $150.000 €$ euros por barrio. En el caso de una extensión, la cantidad máxima se puede aumentar en $100.000 €$, hasta un total de $250.000 €$ por un máximo de 5 años. No se abonan subvenciones inferiores a $5.000 €$.

El municipio debe pagar el $35 \%$ restante, parte del cual puede ser asumido por terceros, con $15 \%$ de los costos elegibles a cargo del municipio y el $20 \%$ restante puede ser financiado por fondos de los estados federales, la Unión Europea o por los actores involucrados en el desarrollo o implementación. La financiación de fondos federales y estatales no puede exceder el $85 \%$ de los costes. Para los municipios financieramente débiles, que tienen que elaborar un plan de seguridad presupuestaria de acuerdo con la ley estatal respectiva, la contribución propia puede reducirse al $5 \%$ de los costos elegibles. En estos casos, la parte de financiación de los fondos federales, estatales y de la Unión Europea puede representar hasta un $95 \%$ del total.

En una primera etapa, el programa se implementó mediante subvenciones para posteriormente ampliarse, incluyendo préstamos de apoyo para la financiación de inversiones planificadas en eficiencia energética urbana. Estos préstamos son: el Préstamo de inversión para municipios (Investitionskredit Kommunen, IKK) y el Préstamo de inversión para empresas municipales y sociales (Investitionskredit Kommunale und Soziale Unternehmen, IKU).

El préstamo IKK financia inversiones sostenibles en eficiencia energética de los sistemas municipales de calefacción, refrigeración, agua y aguas residuales a nivel de barrio, es compatible con otros fondos públicos salvo con los fondos del BMUB. A diferencia del IKK, el préstamo IKU financia la renovación energética de equipamientos e infraestructuras (sin edificios residenciales).

\footnotetext{
${ }^{20}$ En este caso el concepto de barrio no se corresponde con una unidad administrativa específica, hace referencia a un área urbana reconocible por su homogeneidad e identidad social.
} 


\subsubsection{Fiscalidad verde: desgravación fiscal en los trabajos de renovación}

Los propietarios e inquilinos pueden solicitar una desgravación fiscal por los servicios prestados por constructores y profesionales, siempre y cuando no reclamen subsidios públicos por estos servicios. La desgravación fiscal anual máxima concedida es de $1.200 €$. Los propietarios también pueden solicitar, de manera casi inmediata, una desgravación fiscal sobre los gastos del proyecto de rehabilitación.

\subsubsection{Otros instrumentos de apoyo financiero}

- La iniciativa EnEff.Building.2050 proporciona fondos para proyectos piloto que demuestren conceptos ambiciosos de energía para edificios y distritos con el fin de fomentar su adopción generalizada.

- El Gobierno Federal cuenta con un Programa de financiación para redes de calor de cuarta generación (Wärmenetze 4.0) para aprovechar los potenciales de suministro de calor existentes.

\subsection{Instrumentos para la movilización de agentes}

\subsubsection{Información - asesoramiento, planificación y construcción}

Con el fin de garantizar la calidad de la planificación e implementación de los trabajos de renovación, BAFA (la Oficina Federal de Asuntos Económicos y Control de Exportaciones) apoya las consultorías energéticas in situ en edificios residenciales como medida inicial. Las "verificaciones de energía" de las organizaciones de consumidores respaldadas por el Gobierno Federal ofrecen asesoramiento adicional a los inquilinos y propietarios con información económica in situ proporcionada por expertos independientes. También se propone mostrar certificados de rendimiento energético en edificios residenciales, establecer índices de renta ecológica calificados, difundir herramientas de configuración de la rehabilitación a través de Internet o calculadoras de costos.
Muchas de estas acciones están apoyadas por la Agencia Alemana de la Energía (DENA). En concreto, la campaña de renovación "La transición del edificio" es la primera campaña de renovación intersectorial a nivel nacional. Tiene por objeto conectar la demanda con el sector profesional, proporcionando a los propietarios de viviendas unifamiliares y adosadas información detallada sobre todos los aspectos de la mejora de la eficiencia energética y les ayuda a localizar expertos en energía cualificados.

\subsubsection{Asociación por el ahorro de energía}

El Programa de Asociación por el ahorro de energía (desarrollado en Berlín en 1996 por la Agencia de Energía de Berlín) definió un modelo contractual viable, con financiación privada, para garantizar la renovación energética de los edificios públicos, proporcionando asistencia técnica a los propietarios de edificios públicos y lanzando licitaciones para la firma de EPC. Este programa ha sido uno de los catalizadores del mercado EPC en Alemania. La Agencia de Energía de Berlín (BEA) ha desarrollado un modelo de contrato que ha permitido a otros municipios alemanes replicar la experiencia y su presencia como facilitadores del mercado ha sido un elemento esencial para el desarrollo de los mercados de servicios energéticos.

\subsubsection{Apoyo a la investigación sobre Eficiencia Energética en la edificación}

El Gobierno Federal apoya los proyectos de investigación, desarrollo y demostración diseñados para integrar tecnologías de eficiencia y energías renovables en edificios y ciudades como parte de su propio programa de investigación energética y otros programas de investigación sobre políticas en el entorno construido, tanto a nivel urbano como a nivel de edificio. Además de los aspectos tecnológicos, los costos del ciclo de vida y los análisis de rentabilidad también juegan un papel importante. EI VI Programa de investigación en Energía se centra en dos aspectos básicos: innovación en eficiencia energética y en tecnología solar, tanto térmica como fotovoltaica. Los aspectos tecnológicos se complementan con la innovación en 
instrumentos de planificación urbana, promoviendo el enfoque sistémico e integrado de la regeneración energética. ${ }^{21}$

\subsubsection{Otros instrumentos de apoyo a la gestión}

Las siguientes medidas han sido lanzadas por el Gobierno Federal:

- Desde 2016, la campaña Alemania lo hace eficiente $^{22}$ del BMWi ha brindado información sobre los potenciales de eficiencia y las fuentes de financiación, a los agentes involucrados en la transición energética, con un enfoque particular en el sector de la construcción.

\subsection{Aplicabilidad en España}

Las circunstancias históricas y políticas vividas en Alemania a lo largo del siglo XX hacen que su trayectoria y experiencia en materia de rehabilitación del parque edificado sea bastante dilatada y profusa. En cuanto a su realidad territorial y administrativa, encontramos más similitudes que con la realidad francesa. En este sentido, una parte de las medidas desarrolladas podrían ser aplicables al caso español, aunque al contar Alemania con un banco (KfW) dedicado a la renovación del parque edificado, la gestión y financiación se simplifica. A continuación, se indican aquellas medidas que pueden ser aplicables en España.

A. Concepto integral para la renovación urbana a nivel municipal: este programa de financiación del KfW, dirigido a municipios, se entiende como la base de una política de desarrollo urbano sostenible que debe integrar diferentes dimensiones.

B. Además, el Impulso de las redes de calor e integración de las energías renovables fomenta también el desarrollo de proyectos integrales a escala urbana, posibilitando la implementación de redes de calor alimentadas por fuentes de energía renovables. En

\footnotetext{
21 A continuación, se enumeran algunas de las principales iniciativas: EnOB Investigación para edificios de energía optimizada, EnEff Stadt_Investigación para pueblos y ciudades energéticamente eficientes, EnEff: Wärme Iniciativa de investigación sobre Redes de calefacción y refrigeración energéticamente eficientes, Investigación en tecnología termosolar de baja temperatura en edificios, Investigación en
}

esta línea los instrumentos de planificación urbana deberían recoger la planificación energética como parte integral de modelo de ciudad al que se quiere llegar.

C. Financiación de los equipos de gestión de la rehabilitación: se reconoce la dificultad de abordar proyectos a escala de barrio o de conjunto edificado, por eso el KfW ofrece ayudas específicas para el coste de los equipos de gestión.

D. Innovación e investigación en planificación urbana integral para la eficiencia energética. Además de ayudas para financiar la implementación de este tipo de redes, en la estrategia de investigación y desarrollo alemana existe un programa dirigido a la innovación energética (soluciones para gestionar la energía residual, creación de tiendas de energía, puntos de recarga de vehículos, etc.). \&

E. Asociación por el ahorro de energía: la creación de esta figura ha facilitado enormemente la estructuración de la demanda de EPC en el sector público, favoreciendo la existencia de facilitadores de mercado que actúan como mediadores entre las ESCO y sus clientes.

\section{Bibliografía}

ANAH (2010): "Investissements d'avenir, convention Agence nationale de l'habitat (ANAH). Action: "rénovation thermique des logements privés»" JORF $n^{\circ} 0165$ du 20 juillet 2010.

https://www.legifrance.gouv.fr/jorf/id/ JORFTEXT000022497233

BMWi (2017): "National Energy Efficiency Action Plan (NEEAP) 2017 for the Federal Republic of Germany pursuant to Directive 2012/27/EU of the European Parliament and of the Council of 25 October 2012 on energy efficiency". Federal Ministry for Economic Affair (BMWi).

https://ec.europa.eu/energy/sites/ener/files/ documents/de neeap 2017 en.pdf

CASTRILLO, M (2010): "El urbanismo de renovación de grandes conjuntos de vivienda social en Francia, 2004-2008". Revista Proyecto, Progreso, Arquitectura. $\mathrm{N}^{\circ}{ }^{\circ}$. Superposiciones al territorio. Universidad de Sevilla.

almacenamiento de energía, investigación "Futuro de la construcción", Proyectos piloto y redes locales, EfficiencyPlus House, construcción de viviendas experimentales y desarrollo urbano (ExWoSt) la iniciativa Construcción Solar / Ciudad Eficiente en Energía

${ }^{22}$ Página web de la iniciativa: BMWi - Energieeffizienz (deutschland-machts-effizient.de). 
Government of the Federal Republic of Germany (2014): "Report on the long-term strategy for mobilising investment in the renovation of the national building stock pursuant to Article 4 of the Energy Efficiency Directive 2012/27/EUof the European Parliament and of the Council of 25 October 2012".

https://ec.europa.eu/energy/sites/ener/files/ documents/2014 article4 en germany.pdf

MATESANZ, A (2015): "Breves apuntes sobre la Politique de la Ville en Francia (I) y (II)". Link:

http://www2.aq.upm.es/Departamentos/Urbanismo/ blogs/re-hab/rui-europa-apuntes-caso-fr/

MEDDE-MLET (2014): Transposition de l'article 4 de la directive 2012/27/UE. Strategie de mobilisation des investissements dans la renovation energetique des batiments. Direction de l'Habitat de l'urbanisme et des paysages. Ministère de l'Ecologie, du Développement Durable, et de l'Energie (MEDDE) et Ministère du Logement et de l'Egalité des Territoires (MLET). https://ec.europa.eu/energy/sites/ener/files/ documents/2014 article4 fr france.pdf

- (2017): Transposition de l'article 4 de la directive 2012/27/UE. Stratégie à long terme pour mobiliser les investissements dans la rénovation du parc national de bâtiments à usage résidentiel et commercial, public et privé. Direction de l'Habitat de l'urbanisme et des paysages. Ministère de l'Environnement, de l'Energie et de la Mer (MEEM) et Ministère du Logement et de l'Egalité des Territoires (MLET).

https://ec.europa.eu/energy/sites/ener/files/ documents/fr building renov 2017 fr.pdf

Pelegry, E. A. \& MARTíneZ, I. O. (2016): "La transición energética en Alemania". Cuadernos Orkestra 2016/15. Orkestra-Instituto Vasco de Competitividad. https://www.orkestra.deusto.es/images/investigacion/publicaciones/informes/cuadernos-orkestra/ La transici\%C3\%B3n energ\%C3\%A9tica en Alemania Energiewende - Versi\%C3\%B3n web. pdf 